\title{
Risk Factors for Postpartum Septic Pelvic Thrombophlebitis: A Multicenter Cohort
}

\author{
Sarah K. Dotters-Katz, MD ${ }^{1}$ \\ Jennifer L. Thompson, MD ${ }^{3}$ \\ Marcela C. Smid, MD ${ }^{2}$ \\ R. Phillips Heine, $M D^{4}$ \\ ${ }^{1}$ Division of Maternal-Fetal Medicine, University of North Carolina at \\ Chapel Hill, Chapel Hill, North Carolina \\ 2 Division of Maternal-Fetal Medicine, University of Utah, \\ Salt Lake City, Utah \\ ${ }^{3}$ Division of Maternal-Fetal Medicine, Vanderbilt University, \\ Nashville, Tennessee \\ ${ }^{4}$ Division of Maternal-Fetal Medicine, Duke University, \\ Durham, North Carolina
}

Am J Perinatol 2017;34:1148-1151.

\author{
Matthew R. Grace, MD ${ }^{1}$
}

Tracy Manuck, MD, MS ${ }^{1}$

\begin{abstract}
Keywords

- septic pelvic thrombophlebitis

- maternal

- morbidities

- postpartum fever

- postpartum

- infection

Objective The objective of this study was to identify risk factors associated with the development of septic pelvic thrombophlebitis (SPT).

Study Design This is a secondary case-control study of the Eunice Kennedy Shriver National Institute of Child Health and Human Development Maternal-Fetal Medicine Unit Network Cesarean Registry. SPT was defined as suspected infectious thrombosis of the pelvic veins, often persistent febrile illness in the setting of antibiotic therapy for endometritis. Women with SPT were compared with those without SPT using descriptive statistics. Logistic regression models estimated the association between selected risk factors and SPT.

Results Of 73,087 women in the cohort, $89(0.1 \%)$ developed SPT. Women with SPT were more likely to be $<20$ years old ( 33.7 vs. $10.6 \%, p<0.001$ ), black race (58.4 vs. $29.1 \%, p<0.001$ ), and nulliparous ( 51.1 vs. $23.3 \%, p<0.001$ ). Hypertensive disorders of pregnancy $(32.6$ vs. $11.8 \%, p<0.001)$ and multiple gestation $(12.5$ vs. $7.4 \%$, $p=0.03$ ) were also more common in women with SPT. In the multivariable regression model, maternal age $<20$, black race, multiple gestation, and preeclampsia were all significantly associated with increased odds of SPT (adjusted odds ratio [aOR]: 1.96, 95\% confidence interval [Cl]: 1.22, 3.14; aOR: 2.6, 95\% Cl: $1.68,4.02$; aOR: $2.10,95 \% \mathrm{Cl}$ : 1.13, 3.88; aOR: 2.91, 95\% Cl: 1.86, 4.57).

Conclusion SPT is a rare pregnancy complication. Our analysis confirmed known risk factors (e.g., infections, cesarean delivery), and identified novel ones, including black race, young age, preeclampsia, and multiple gestation.
\end{abstract}

Septic pelvic thrombophlebitis (SPT) is a rare, yet serious complication that occurs in the postpartum or postoperative time period. The frequency is varied, ranging from 1:500 to 2,000 cesarean deliveries and 1:9,000 vaginal deliveries. ${ }^{1-3}$ However, these data are variable across institutions and over time at the same institution. ${ }^{1,4-6}$
SPT is considered when a woman presents with abdominal or pelvic pain and continues to be febrile in the postpartum period after 3 to 4 days of appropriate antibiotic therapy and other infectious sources have been ruled out. ${ }^{7,8}$ Most often a diagnosis of exclusion, experts recommend that the diagnosis be confirmed with visualization of a thrombus accepted

June 12, 2017

published online

July 13,2017
Copyright $\odot 2017$ by Thieme Medical Publishers, Inc., 333 Seventh Avenue, New York, NY 10001, USA. Tel: +1(212) 584-4662.
DOI https://doi.org/ 10.1055/s-0037-1604245. ISSN 0735-1631. 
in the pelvic veins on computed tomography (CT) scan. ${ }^{1,8}$ Risk factors commonly associated with SPT include cesarean delivery, chorioamnionitis, and endometritis. ${ }^{8-10}$ However, these studies are all single institution and thus have limited numbers of women with SPT.

The purpose of this study is to describe the frequency of SPT and to determine whether specific demographic, antenatal, or delivery characteristics are associated with the development of SPT. Finally, we sought to describe maternal complications associated with SPT.

\section{Methods}

This is a case-control study of the Eunice Kennedy Shriver National Institute of Child Health and Human Development Maternal-Fetal Medicine Unit Cesarean Registry. The original study recruited 73,257 women who delivered via cesarean or vaginal birth after cesarean and was conducted from 1999 to 2002 in 19 academic centers, and has been previously published. ${ }^{11}$ Data collection was performed by trained chart abstractors (nurses) who were blinded to delivery mode. For the purposes of this secondary analysis, we included all women from the original study who delivered at more than 23 weeks. This study was reviewed by our local Institutional Review Board (IRB) and deemed exempt from IRB oversight, as we were provided a deidentified dataset on which to conduct these analyses.

SPT was defined as a suspected infectious thrombosis of the pelvic veins and/or persistent febrile illness in the setting of antibiotic therapy for endometritis. We defined cases as women with SPT. Controls were defined as women without SPT. Risk factors examined included maternal demographic, antenatal, and intrapartum characteristics. Maternal complications of interest included: need for repeat laparotomy, hysterectomy, wound complications, venous thromboembolism (deep vein thrombosis [DVT] and pulmonary embolus [PE]), readmission, and maternal death.

Demographic, antenatal, and intrapartum characteristics of women with SPT were compared with those without SPT to identify risk factors. Data analysis was performed by Student's t-test, Fisher's exact, or Wilcoxon's rank-sum test as appropriate. Maternal complications were also compared among women with and without SPT using bivariate analysis. Logistic regression models were used to estimate odds ratios (ORs) for the association between selected risk factors and SPT. Stepwise regression with backward elimination was performed to select an adjusted model. Main effects were retained in the model if $p<0.2$. Analyses were performed using STATA (version 14, StataCorp, College Station, TX).

\section{Results}

Of the 73,087 women in the study, $89(0.12 \%)$ developed SPT. Of these, 87 out of 89 (98\%) occurred following cesarean delivery. Women who developed SPT were more likely to be younger than 20 years old, non-Hispanic black race, have public insurance, and nulliparous (all $p<0.001$ ) compared with women who did not develop SPT ( - Table 1). Pregestational diabetes was not a risk factor for SPT in this population $(p=0.52)$. However, twin gestation and obesity were both significantly associated with SPT ( $p=0.03$ and $p=0.02$, respectively). Women who developed SPT were more likely to have labored, had chorioamnionitis, delivered preterm $<32$ weeks, and delivered via cesarean delivery when compared with women who did not develop SPT (all $p=0.001$ or less).

In the multivariable regression model, OR of SPT were significantly increased among women delivering by cesarean (aOR: 6.25, 95\% CI: 1.94-20.1) and those with chorioamnionitis (adjusted OR [aOR]: 4.8, 95\% CI: 2.95-7.86). Non-Hispanic black race, maternal age $<20$ years, hypertensive disorders of pregnancy, and twin gestation were also significantly associated with increased odds of SPT (- Table 2 ).

SPT was not associated with an increased need for mechanical ventilation or maternal death ( - Table 3 ). Other morbidities such as wound complications, DVT, and PEs were all significantly more common among women with SPT compared with those without (all $p<0.001$ ). Repeat exploratory laparotomy and peripartum hysterectomy were also more common among women diagnosed with SPT (-Table 3 ). Among women with SPT, more than one in five required a blood transfusion, compared with only $2.4 \%$ of women who did not have SPT ( - Table $3, p<0.001$ ).

\section{Discussion}

We found SPT to be uncommon, diagnosed in $0.1 \%$ of this high-risk cohort, a frequency similar to previous reports. ${ }^{1-3}$ However, we did identify some novel risk factors for development of SPT, including age younger than 20 years old, nonHispanic black race, and multiple gestation, and confirmed known risk factors for SPT, including cesarean section and chorioamnionitis. In addition, we found that women with SPT are associated with other severe postpartum complications including blood transfusion, wound complications, hysterectomy, and repeat laparotomy.

Others have attempted to identify risk factors for the development of SPT. Preceding peripartum infections appear to be a clear risk factor. Rouse et al identified SPT to be significantly associated with chorioamnionitis, as did Isler et al. ${ }^{12,13}$ Gibbs et al noted that endometritis, specifically after cesarean delivery, increased the incidence of SPT to $2 \% .{ }^{10}$ Another subset of studies have identified endothelial dysfunction/damage as a preceding risk factor. Isler et al who found that $45 \%$ of women with SPT had a hypertensive disorder of pregnancy, compared with 12 to $13 \%$ of women without SPT. ${ }^{12}$ Hypertensive disorders of pregnancy are associated with underlying endothelial dysfunction, part of Virchow's triad, which may help explain its strong association between SPTs. ${ }^{4,12}$ Diabetes and chronic hypertension, two disorders not associated with endothelial damage, were not associated with SPT in either our cohort nor that of Isler et al. ${ }^{12}$ Finally, other authors have queried if women who develop SPT have some degree of underlying thrombophilia. In our cohort, there were high rates of DVT and PE among the women with SPT. This might also explain the association between SPT and hypertensive disorders of pregnancy, in that women with underlying thrombophilias are more prone to develop preeclampsia 
1150 Risk Factors for Septic Pelvic Thrombophlebitis Dotters-Katz et al.

Table 1 Demographic and intrapartum factors associated with septic pelvic thrombophlebitis in MFMU Cesarean Registry $(n=73,087)$

\begin{tabular}{|c|c|c|c|}
\hline & $\begin{array}{l}\text { Septic pelvic thrombophlebitis } \\
n=89(\%)\end{array}$ & $\begin{array}{l}\text { No septic pelvic thrombophlebitis } \\
n=72,998(\%)\end{array}$ & $p$-Value \\
\hline \multicolumn{4}{|l|}{ Demographic } \\
\hline \multicolumn{4}{|l|}{ Maternal age $(y)$} \\
\hline$<20$ & $30(33.7)$ & $7,719(10.6)$ & \multirow[t]{3}{*}{$<0.001$} \\
\hline $20-34$ & $53(59.6)$ & $54,867(75.2)$ & \\
\hline$\geq 35$ & $6(6.7)$ & $10,412(14.3)$ & \\
\hline Non-Hispanic black race & $52(58.4)$ & $21,270(29.1)$ & $<0.001$ \\
\hline Public insurance & $36(40.5)$ & $15,389(21.1)$ & $<0.001$ \\
\hline Nulliparous & $45(51.1)$ & $16,880(23.3)$ & $<0.001$ \\
\hline Pregestational diabetes & $1(1.1)$ & $1,531(2.1)$ & 0.52 \\
\hline Chronic hypertension & $3(3.4)$ & $1,851(2.5)$ & 0.62 \\
\hline Smoking & $14(15.7)$ & $10,275(14.1)$ & 0.67 \\
\hline Body mass index $\geq 30$ & $61(72.6)$ & $41,072(60.1)$ & 0.02 \\
\hline Twin gestation & $12(13.5)$ & $5,362(7.4)$ & 0.03 \\
\hline Hypertensive disorders or pregnancy & $29(32.6)$ & $8,577(11.8)$ & $<0.001$ \\
\hline \multicolumn{4}{|l|}{ Intrapartum } \\
\hline Preeclampsia & $29(32.6)$ & $8,577(11.8)$ & $<0.001$ \\
\hline Cesarean delivery & $87(97.8)$ & 59,755 (81.9) & $<0.001$ \\
\hline Chorioamnionitis & $26(29.1)$ & $4,034(5.5)$ & $<0.001$ \\
\hline Labor & $67(75.3)$ & $41,771(57.2)$ & 0.001 \\
\hline \multicolumn{4}{|l|}{ Gestational age at delivery (wk) } \\
\hline $23-36$ & $20(22.7)$ & $15,509(21.3)$ & \multirow[t]{3}{*}{0.05} \\
\hline $37-41$ & $53(60.2)$ & $50,437(69.2)$ & \\
\hline$\geq 42$ & $15(17.1)$ & $6,896(9.5)$ & \\
\hline
\end{tabular}

Abbreviation: MFMU, Maternal-Fetal Medicine Unit.

Table 2 aOR for risk factors associated with development of septic pelvic thrombophlebitis in MFMU Cesarean Registry $(n=73,054)$

\begin{tabular}{|c|c|c|}
\hline & aOR $(95 \% \mathrm{Cl})$ & $p$-Value \\
\hline \multicolumn{3}{|l|}{ Maternal age $(y)^{\mathrm{a}}$} \\
\hline$<20$ & $1.96(1.22,3.14)$ & 0.006 \\
\hline$\geq 35$ & $0.69(0.29,1.61)$ & 0.39 \\
\hline Non-Hispanic black race ${ }^{b}$ & $2.60(1.68,4.02)$ & $<0.001$ \\
\hline Cesarean delivery ${ }^{\mathrm{C}}$ & $6.25(1.94,20.1)$ & 0.002 \\
\hline Chorioamnionitis & $4.81(2.95,7.86)$ & $<0.001$ \\
\hline $\begin{array}{l}\text { Hypertensive disorders } \\
\text { of pregnancy }\end{array}$ & $2.91(1.86,4.57)$ & $<0.001$ \\
\hline Public insurance ${ }^{d}$ & $1.98(1.28,3.04)$ & 0.002 \\
\hline Multiple gestation & $2.10(1.13,3.88)$ & 0.019 \\
\hline Labor & $1.79(1.06,3.00)$ & 0.029 \\
\hline
\end{tabular}

Abbreviations: aOR, adjusted odds ratio; $\mathrm{Cl}$, confidence interval; $\mathrm{MFMU}$,

Maternal-Fetal Medicine Unit.

aReferent group: age 20 to 34 years.

${ }^{\mathrm{b}}$ Referent group: other race/ethnicities.

${ }^{\mathrm{C}}$ Referent group: vaginal birth after cesarean.

${ }^{\mathrm{d}}$ Referent group: other payer.

Table 3 Maternal complications associated with septic pelvic thrombophlebitis in MFMU Cesarean Registry $(n=73,087)$

\begin{tabular}{|l|l|l|l|}
\hline & $\begin{array}{l}\text { Septic pelvic } \\
\text { thrombophlebitis } \\
\boldsymbol{n}=\mathbf{8 9}(\%)\end{array}$ & $\begin{array}{l}\text { No septic pelvic } \\
\text { thrombophlebitis } \\
\boldsymbol{n}=\mathbf{7 2 , 9 9 8}(\%)\end{array}$ & $p$-Value \\
\hline Readmission & $3(3.3)$ & $916(1.3)$ & 0.07 \\
\hline $\begin{array}{l}\text { Mechanical } \\
\text { ventilation }\end{array}$ & $7(7.9)$ & $207(7.8)$ & 0.99 \\
\hline $\begin{array}{l}\text { Maternal } \\
\text { death }\end{array}$ & 0 & $37(0.1)$ & 0.83 \\
\hline $\begin{array}{l}\text { Repeat } \\
\text { exploratory } \\
\text { laparotomy }\end{array}$ & $7(7.9)$ & $181(0.3)$ & $<0.001$ \\
\hline $\begin{array}{l}\text { Peripartum } \\
\text { hysterectomy }\end{array}$ & $3(3.3)$ & $338(0.5)$ & $<0.001$ \\
\hline $\begin{array}{l}\text { Wound } \\
\text { complication }\end{array}$ & $20(22.5)$ & $775(1.1)$ & $<0.001$ \\
\hline $\begin{array}{l}\text { Pulmonary } \\
\text { embolism }\end{array}$ & $6(6.7)$ & $97(0.1)$ & $<0.001$ \\
\hline $\begin{array}{l}\text { Deep vein } \\
\text { thrombosis }\end{array}$ & $8(9.0)$ & $138(0.2)$ & $<0.001$ \\
\hline Endometritis & $64(71.9)$ & $3,662(5.0)$ & $<0.001$ \\
\hline $\begin{array}{l}\text { Blood } \\
\text { transfusion }\end{array}$ & $19(21.4)$ & $1,760(2.4)$ & $<0.001$ \\
\hline
\end{tabular}

Abbreviation: MFMU, Maternal-Fetal Medicine Unit. 
and possibly SPT as well. ${ }^{12,14}$ In reality, there are probably risk multiple factors needed for the development of SPT, including some combination of infection, inflammation, and thrombophilia involve. Data from this population by Hauth, examining DVT and PE risk, also allude to this. ${ }^{15}$

These data provide a large, multicenter population-based cohort of SPT with uniform, prospective data collection. Due to the multicenter nature of the study, the population is more diverse, and thus, the results may be more applicable to the general population than previous single-center studies. As a large proportion of the women within this study underwent cesarean delivery, a known risk factor for SPT, we were able to better study a rare outcome. Finally, as the data were rigorously collected by trained study nurses, the risk of observer bias is low.

This study is not without limitations. The original study definition of SPT used only clinical diagnostic criteria and did not require imaging confirmation for diagnosis. Of the 89 women with SPT, 53 (60\%) did have a CT scan, though the indication for the CT scan is not available in the data. Thus, we are unable to determine if cases of SPT were confirmed by imaging. We are also limited by the temporality of maternal complications in relation to the diagnosis of SPT, which confounds the ability to identify a "risk factor" from a "complication" in some instances. For example, it is unknown if a woman with SPT and a blood transfusion first received the blood transfusion, or was first diagnosed with SPT. Thus, we can make associations but cannot determine causality. In addition, this is a secondary analysis. Finally, due to the relative rarity of maternal complications associated with SPT, regression modeling was not possible.

In conclusion, this case-control study confirms known risk factors for SPT including chorioamnionitis, hypertensive disorders of pregnancy, and cesarean delivery. We also identify additional risk factors associated with this serious medical complication, including young maternal age, African American race, and multiple gestation. In addition, we highlight an association with postpartum complications, including blood transfusion, PE, wound infection, and hysterectomy. However, further studies are needed to confirm these associations. Providers caring for women with multiple SPT risk factors and persistent postpartum fevers should have a low threshold to evaluate, and consider presumptive treatment for SPT.

Note

This article was presented in part at the 37th Annual Society of Maternal Fetal Medicine Meeting in 2017, Las Vegas, Nevada as a poster presentation.
Funding

None.

Conflict of interest

None.

\section{References}

1 Brown CE, Stettler RW, Twickler D, Cunningham FG. Puerperal septic pelvic thrombophlebitis: incidence and response to heparin therapy. Am J Obstet Gynecol 1999;181(01):143-148

2 Duff P, Gibbs RS. Pelvic vein thrombophlebitis: diagnostic dilemma and therapeutic challenge. Obstet Gynecol Surv 1983; 38(06):365-373

3 Dunnihoo DR, Gallaspy JW, Wise RB, Otterson WN. Postpartum ovarian vein thrombophlebitis: a review. Obstet Gynecol Surv 1991;46(07):415-427

4 Collins CG. Suppurative pelvic thrombophlebitis. A study of 202 cases in which the disease was treated by ligation of the vena cava and ovarian vein. Am J Obstet Gynecol 1970;108(05):681-687

5 Collins CG, MacCALLUM EA, Nelson EW, Weinstein BB, Collins JH. Suppurative pelvic thrombophlebitis. I. Incidence, pathology, and etiology; a study of 70 patients treated by ligation of the inferior vena cava and ovarian vessels. Surgery 1951;30(02): 298-310

6 Witlin AG, Sibai BM. Postpartum ovarian vein thrombosis after vaginal delivery: a report of 11 cases. Obstet Gynecol 1995;85(5 Pt 1):775-780

7 Garcia J, Aboujaoude R, Apuzzio J, Alvarez JR. Septic pelvic thrombophlebitis: diagnosis and management. Infect Dis Obstet Gynecol 2006;2006:15614

8 Jaiyeoba O. Postoperative infections in obstetrics and gynecology. Clin Obstet Gynecol 2012;55(04):904-913

9 Duff P. Septic Pelvic Vein Thrombophlebitis. St. Louis, MO: Mosby Year Book; 1993

10 Gibbs RS, Jones PM, Wilder CJ. Antibiotic therapy of endometritis following cesarean section. Treatment successes and failures. Obstet Gynecol 1978;52(01):31-37

11 Landon MB. Predicting uterine rupture in women undergoing trial of labor after prior cesarean delivery. Semin Perinatol 2010; 34(04):267-271

12 Isler CM, Rinehart BK, Terrone DA, Crews JH, Magann EF, Martin JN Jr. Septic pelvic thrombophlebitis and preeclampsia are related disorders. Hypertens Pregnancy 2004;23(01):121-127

13 Rouse DJ, Landon M, Leveno KJ, et al; National Institute of Child Health And Human Development, Maternal-Fetal Medicine Units Network. The Maternal-Fetal Medicine Units cesarean registry: chorioamnionitis at term and its duration-relationship to outcomes. Am J Obstet Gynecol 2004;191(01):211-216

14 Rath W. Pre-eclampsia and inherited thrombophilia: a reappraisal. Semin Thromb Hemost 2011;37(02):118-124

15 Hauth J. MFMU cesarean registry: thromboembolism-occurrence and risk factors in 39,285 cesarean births. Am J Obstet Gynecol 2003;189(06):s120 